\title{
Results of Nerve Transfer in C5-C6 Traumatic Brachial Plexus Palsy
}

\author{
Yacine Talbi* \\ Said Ait Messaoudene Military Hospital, Algeria
}

*Corresponding author: Yacine Talbi, Said Ait Messaoudene Military Hospital, BP 83, Staoueli, Algeria

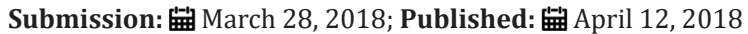

\section{Introduction}

Brachial plexus injuries involve male patients $90 \%$ of time, and are responsible of partial or total loss of motion in the upper extremity. C5-C6 traumatic brachial plexus injury is responsible of shoulder and elbow flexion palsy.

In case of C5-C6 brachial plexus palsy, in addition to classic nerve repair by root graft there are also nerve transfers or tendon transfers.

Nerve transfers have been used with success for reconstruction of brachial plexus injuries [1].

Oberlin et al. [2] described in 1994 a technic for reestablishment of elbow flexion after transfer of motor fascicle of ulnar nerve to the nerve of the biceps. The results of this technic showed MRC grade M3 or M4 strength in 24 of 32 patients.

Since 2007, we used a double transfer for the restoration of elbow flexion (motor fascicles of the ulnar nerve to the biceps nerve and motor fascicles of the median nerve to the brachial nerve) for all C5-C6 palsy. The purpose of this present study is to present the result of the double nerve transfer for restoration of elbow flexion in C5-C6 brachial plexus palsy.

\section{Materials and Methods}

Between 2007 and 2013, 21 post-traumatic C5-C6 brachial plexus injury with complete elbow flexion palsy were included in this study.

There were 19 men and 02 women; the mean age was 36 years (range 08-65 years). The most common mechanism of injury motor vehicle collision (17 patients), followed by motorcycle accident (03 patients) and a road accident (1 patient). Surgery was performed at mean of 15 months after injury (range 03-25 months). All patients benefited from a double nerve transfer (transfer of motor fascicles of the ulnar nerve to the nerve of the biceps with same diameter, combined with a transfer of motor fascicles of the median nerve to the nerve of the brachial with same diameter) "Figure 1 \& 2" according to the technique of Oberlin [2], with the objective of restoring elbow flexion.
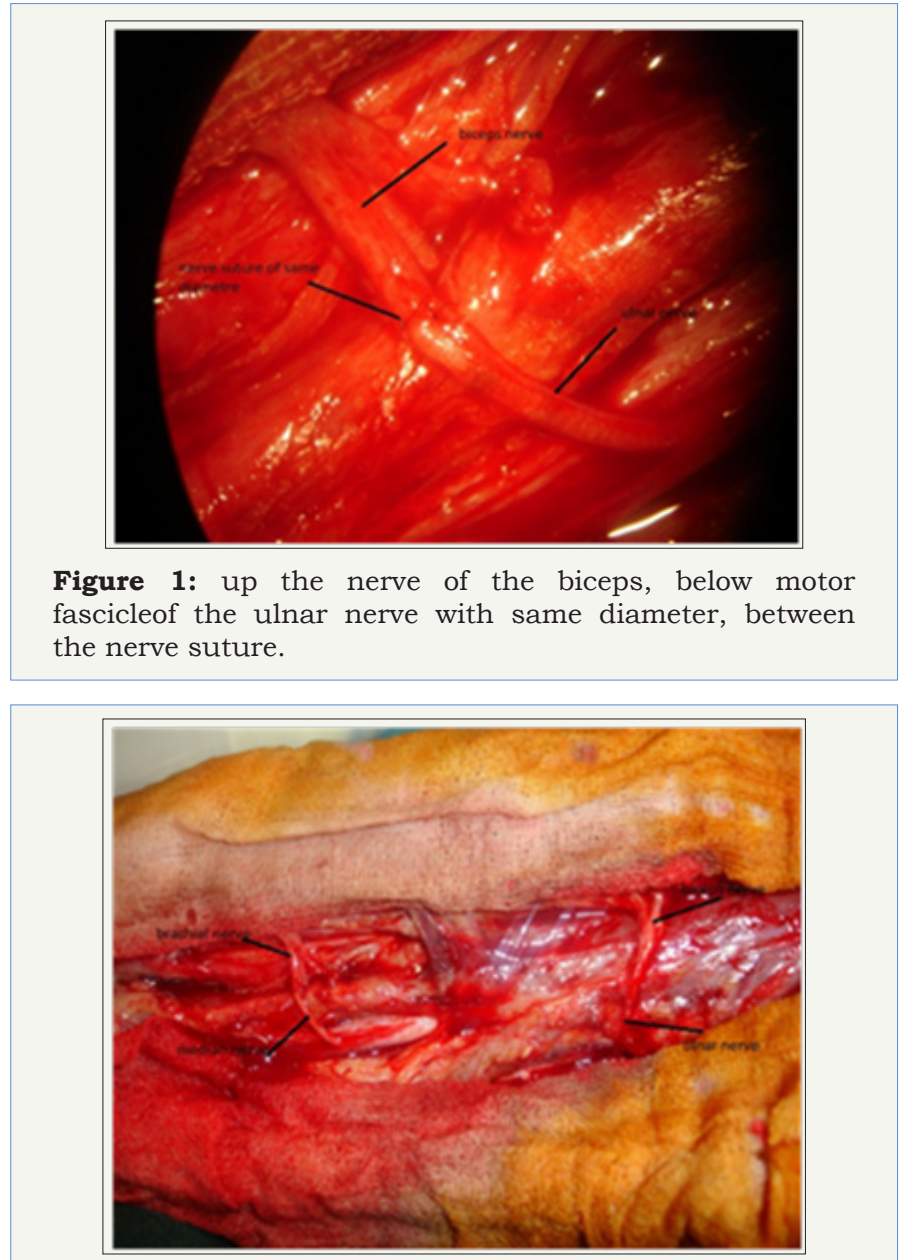

Figure 2: left; suture of the ulnar nerve with The nerve of the biceps, right; suture of the median nerve with the brachial nerve

For the shoulder palsy, we associated with the double transfer, a transfer of the accessory spinal nerve to the suprascapular nerve in only one case, in a girl 8 years old. for the other patients we associated a $\mathrm{C} 5$ root graft on the first trunk, if the C5 root was not avulsed. 
Clinical evaluation: all patients underwent preoperative clinical evaluation including, elbow flexion strength testing, 2-point discrimination. Postoperative evaluation included elbow flexion strength testing (The elbow flexion strength was evaluated by using hand dynamometer placed on the distal part of the radius), 2-point discrimination and testing of opposite side elbow flexion.

Postoperative management: Postoperatively bandage immobilizes shoulder, elbow at $90^{\circ}$ flexion for 21 days. After 3 weeks, patients are referred to physical therapist.

Table 1: clinical series of C5-C6 brachial plexus palsy.

\section{Results}

The results were assessed by evaluating the recovery of strength of elbow flexion, according to the British Medical Research Council (BMRC) rating.

The first visible contractions (M2) were observed between the $4^{\text {th }}$ and $6^{\text {th }}$ postoperative month, and flexion against gravity was observed between the $7^{\text {th }}$ and $8^{\text {th }}$ postoperative month (Table 1 ), but for flexion against resistance it was necessary to wait between the $9^{\text {th }}$ and $12^{\text {th }}$ postoperative month.

\begin{tabular}{|c|c|c|c|c|c|c|c|}
\hline Patient & Sexe & Age & Side & Preoperative & Follow-up & Strength & Strength \\
\hline & & & & Delay (month) & (month) & (Kg) & opposite side \\
\hline 1 & male & 33 & righrt & 11 & 14 & 15 & 23 \\
\hline 2 & male & 21 & right & 7 & 17 & 13 & 20 \\
\hline 3 & male & 26 & right & 9 & 22 & 14 & 24 \\
\hline 4 & male & 35 & left & 3 & 29 & 18 & 29 \\
\hline 5 & male & 24 & right & 12 & 20 & 20 & 32 \\
\hline 6 & female & 8 & left & 4 & 18 & 4 & 7 \\
\hline 7 & male & 39 & left & 9 & 60 & 23 & 30 \\
\hline 8 & male & 21 & right & 12 & 11 & 13 & 21 \\
\hline 9 & male & 31 & left & 13 & 18 & 26 & 22 \\
\hline 10 & male & 28 & left & 7 & 14 & 25 & 18 \\
\hline 11 & male & 21 & right & 6 & 19 & 20 & 27 \\
\hline 12 & male & 33 & right & 4 & 108 & 19 & 29 \\
\hline 13 & male & 25 & right & 7 & 12 & 17 & 26 \\
\hline 14 & female & 24 & left & 6 & 46 & 10 & 22 \\
\hline 15 & male & 28 & left & 10 & 18 & 15 & 27 \\
\hline 16 & male & 30 & left & 12 & 35 & 21 & 29 \\
\hline 17 & male & 65 & right & 9 & 22 & 0 & 17 \\
\hline 18 & male & 34 & left & 7 & 36 & 13 & 26 \\
\hline 19 & male & 33 & left & 25 & 31 & 0 & 31 \\
\hline 20 & male & 25 & right & 6 & 12 & 17 & 25 \\
\hline 21 & male & 36 & left & 5 & 17 & 16 & 28 \\
\hline
\end{tabular}

The elbow flexion strength was evaluated by using hand dynamometer placed on the distal part of the radius (Table 1).
Overall, on the 21 operated patients, the double nerve transfer has allowed good flexion of elbow (M4-M5) in 19 cases "Figure 3 \& 4 " and we did not get any contractions in 02 cases (M0). 


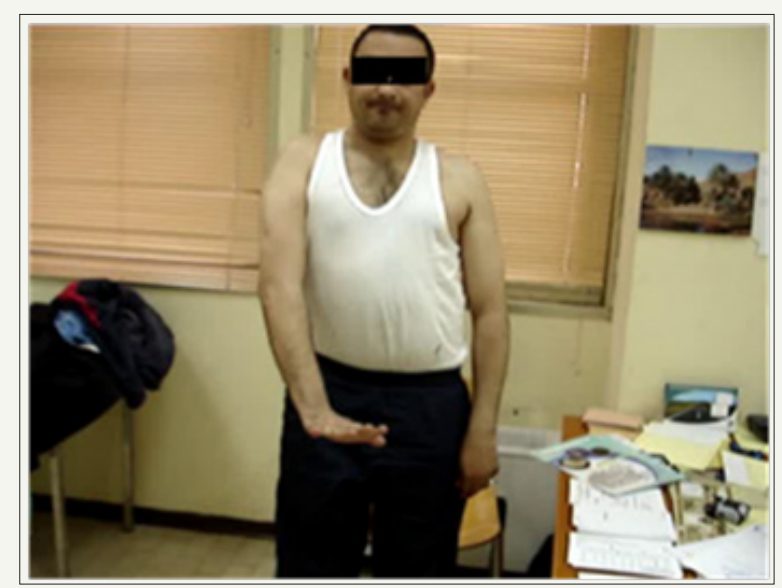

Figure 3: preoperative C5-C6 Brachial plexus palsy.

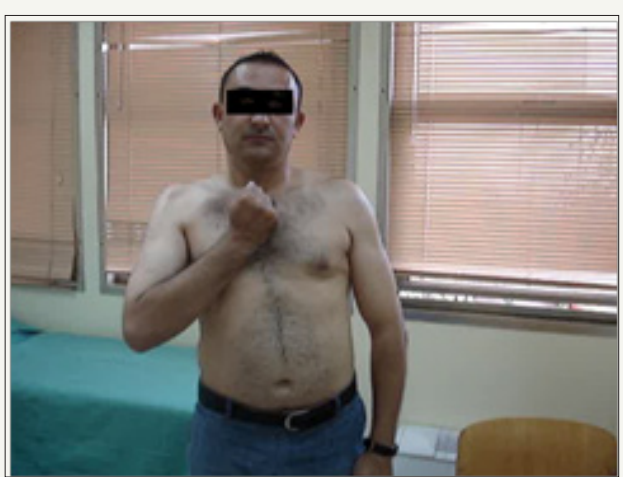

Figure 4: post-operative result.

We report one sensory deficits in the median nerve area, it was a woman 24-year-old. The deficit in the median nerve was hypoesthesia of the first three fingers who recovered after 05 weeks.

\section{Discussion}

According to Midha [3] brachial plexus injuries occur following $0.67 \%-1.3 \%$ of motor vehicle collision and $4.2 \%$ of motorcycle accident. In our series $80.95 \%$ (17 patients) of C5-C6 brachial plexus palsy occurred following motor vehicle collision.

The root grafts requires axonal regeneration over long distances, and are confronted to the problem nerve growth error. The results of the various published series prove it, Alnot et al. In 1998 , reported a recovery rate of $53 \%$ in 15 cases [4], Klein and Tiel in 2005 reported a recovery rate of $55 \%$ for 67 patients [5].

When there is a root avulsion the use of nerve transfers becomes a necessity, the accessory spinal nerve can be used which gives $75 \%$ good results according to Alnot [4], or the intercostal nerves Bouloudnine [6].

In a comparative study, Sokolowski et al. [7] presented the comparative results between root grafts and transfer of motor fascicles from the ulnar nerve to the biceps nerve, and obtained $47 \%$ results at M3 for root grafts versus $88 \%$ for the nerve transfer.
Another study was carried out by Coulet et al. [8] between transfer of the intercostal nerves and transfer of motor fascicles from the ulnar nerve to the biceps nerve and obtained $87 \%$ strength at M3 for ulnar nerve transfer on nerve of the biceps versus 59\% for the intercostal nerves transfer to the nerve of the biceps.

The principle of nerve transfer is the transfer of a motor nerve to another motor nerve without nerve growth error between sensory and motor nerves, and the proximity of the target [1].

The Oberlin technique seems to give better results than other types of nerve transfer $[7,8]$.

Other authors published the results of the double transfer of motor fascicles from the ulnar nerve to the biceps nerve associated with the transfer of motor fascicle from the median nerve to the brachial nerve, Makinnon et al. [9] reported 66\% results at M4. Estrella EP [10], Ray WZ [11], Goubier [12] confirm results up to $80 \%$ at M4.

Carlsen et al. [13] compared the results between single and double transfer with rates of $67 \%$ for single and $80 \%$ for double transfer.

Oberlin et al. [1] reported the results of two series of single and double transfer with respectively rates of $60 \%$ and $79 \%$ without a comparative study between the two series. 
Martin et al. [14] compared the results between single and double transfer and found no difference between the two groups.

Barthel et al. [15] compares the results between single and double transfer and finds $60 \%$ strength at M4 for single and $85 \%$ for double transfer.

The proximity of the ulnar nerve offered an easily accessible donor to the biceps and the proximity of the median nerve offered an accessible donor to the brachialis nerve, this double transfer represented a significant step forward in the evolution of nerve transfers for upper brachial plexus palsy [1].

In our series, we report two failures at M0 (10\%), $19 \operatorname{good}$ results at M4-M5 (90\%) and one sensory deficits judged not inconvenient by the patients. The first failure was a man 65 years old; the failure was put on the account of the advanced age. The second failure was a patient operated 25 months after trauma; probably the delay of the management must had a primary role for the failure. Despite the evidence that the double transfer gives good results without functional downgrade, some surgeons continue to perform a single nerve transfer of lone ulnar transfer to the biceps, the argument is that preservation of native innervation of brachialis muscle allows the possibility of spontaneous recovery [16].

Outcomes in the featured cases obtained by the double transfer as well as the very low rate of sequels linked to the sample; make this technique a good indication in the treatment of the upper brachial plexus palsy [17].

\section{References}

1. Oberlin C, Durand S, Belheyar Z, Shafi M, David E, et al. (2009) Les transferts nerveux dans les paralysies du plexus brachial. Chir Main 28: $1-9$.

2. Oberlin C, Beal D, Leechavengvongs S, Salon A, Dauge MC, et al. (1994) Nerve transfer to biceps muscle using a part of ulnar nerve for C5-C6 avulsion of the brachial plexus: anatomical study and report of four cases. J Hand Surg Am 19(2): 232-237.

3. Midha R (1997) Epidemiology of brachial plexus injuries in a multitrauma population. Neurosurgery 40(6): 1182-1189.

4. Alnot JY, Rostoucher P, Oberlin C, Touam C (1998) Les paralysies traumatiques $\mathrm{C} 5-\mathrm{C} 6$ et $\mathrm{C} 5-\mathrm{C} 6-\mathrm{C} 7$ du plexus brachial de l'adulte par lésions supracla-viculaires. Rev Chir Orthop Reparatrice Appar Mot 84: 113-123.
5. Kline DG, Tiel RL (2005) Direct plexus repair by grafts supplemented by nerve transfers. Hand Clin 21(1): 55-69.

6. Boulouednine M (1997) Paralysies post traumatiques du plexus brachial. Etude et résultats du transfert des nerfs intercostaux par anastomose directe dans la réanimation de la flexion du coude. A propos de 20 cas. Thèse Méd Montpellier 1: 58.

7. Socolovsky M, Martins RS, Di Masi G, Siqueira M (2012) Upper brachial plexus injuries: graft versus ulnar fascicle transfer to restore biceps muscle function. Neurosurgery 71:227-232.

8. Coulet B, Boretto JG, Lazerges C, Chammas M (2010) A comparison of intercostal and partial ulnar nerve transfers in restoring elbow flexion following upper brachial plexus injury (C5-C6+/-C7). J Hand Surg Am 35(8): 1297-1303.

9. Mackinnon SE, Novak PT, Myckatyn T, Tung T (2005) Results of reinnervation of the biceps and brachialis muscles with a double fascicular transfer for elbow flexion. J Hand Surg Am 30(5): 978-985.

10. Estrella EP (2011) Functional outcome of nerve transfers for upper-type brachial plexus injuries. J Plast Reconstr Aesthet Surg 20: 1-7.

11. Ray WZ, Pet MA, Yee A, Mackinnon SE (2011) Double fascicular nerve transfer to the biceps and brachialis muscles after brachial plexus injury: clinical outcomes in a series of 29 cases. J Neurosurgery 114(6): 15201528.

12. Goubier JN, Teboul F (2007) Technique of the double nerve transfer to recover elbow flexion in C5-C6 or C5 to C7 brachial plexus palsy. Tech Hand up Extrem Surg 11(1): 15-17.

13. Carlsen B, Bishop A, Spinner R, Shin A (2011) Comparison of single and double nerve transfer for elbow flexion after brachial plexus injury. Plast Reconstr Surg 127(1): 269-276.

14. Martins RS, Siqueira MG, Heise CO, Foroni L, Teixera MJ (2013) A prospective study comparing single and double fascicular transfer to restore elbow flexion after brachial plexus injury. Neurosurgery 72(5): 709-714.

15. Barthel PY, Barbary S, Breton A, Apredoaei C, Dap F, Mansat P, et al. (2014) Restauration de la flexion du coude dans les paralysies traumatiques C5-C6 et C5-C6-C7. Etude bicentrique rétrospective comparant simple versus double neurotisation. Ann Chir Main 33(3): 211-218.

16. Addas BM, Midha R(2009) Nerve transfers for severe nerve injury. Neurosurg Clin N Am 20(1): 27-38.

17. Loy S, Bathia A, Asfazadourian A, Oberlin C (1997) Transfert de fascicule du nerf ulnaire sur le nerf du muscle biceps dans les avulsions C5-C6 ou C5-C6-C7 du plexus brachial. Ann Chir Main 16(4): 275-284.
Creative Commons Attribution 4.0 International License

For possible submissions Click Here

\section{Submit Article}

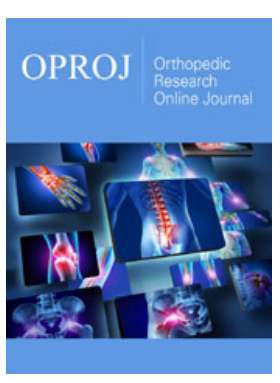

Orthopedic Research Online Journal

\section{Benefits of Publishing with us}

- High-level peer review and editorial services

- Freely accessible online immediately upon publication

- Authors retain the copyright to their work

- Licensing it under a Creative Commons license

- Visibility through different online platforms 